Session 2249

\title{
An Innovative Approach to Curriculum Development for Engineering Technology Programs
}

\author{
Saleh M. Sbenaty, Melvin J. Montgomery \\ Middle Tennessee State University/Jackson State Community College
}

\begin{abstract}
This paper describes a curriculum development and delivery approach that improves engineering and technology education and increase student interests in pursuing these programs. This is one of the goals of the three-year NSF-funded grant (\$1.8 million) titled "The South-East Advanced Technological Education Consortium, SEATEC." The consortium is a collaborative effort of five different teams across Tennessee. Each team includes multi-disciplinary faculties from two-year technical colleges, industry partners, university partners, and high school tech-prep teachers. The paper documents activities that have brought national attention to the project and provided opportunities for SEATEC team members to exchange ideas with others working in the area of case studies.
\end{abstract}

\section{Introduction}

The technological revolution that has taken place in recent years, and is continuing today, has created a strong impetus for improvements in educational methods. This has led to alternatives to the traditional classroom lecture method. One alternative is the case study. Case studies are used extensively in the medical, law, and business fields. However, the use of case studies has been somewhat limited in engineering and technology education, particularly in two-year technical colleges. The SEATEC grant is funded by NSF is for the purpose of promoting case studies as a teaching tool in engineering and technology education. To accomplish this, the following SEATEC goals have been established:

1. To provide national leadership for the development and implementation of case-based instruction in technology and engineering education.

2. To provide opportunities for continuous and appropriate professional development of participating faculty.

3. To assess the effectiveness of the case study approach in teaching technology-related curriculum.

4. To nationally disseminate information related to SEATEC activities, materials, and results, including outcomes of the use of case studies in field-test setting.

\section{The SEATEC Consortium}

The SEATEC consortium is a collaborative effort of five different teams across Tennessee. Each team includes multi-disciplinary faculties from two-year technical colleges, industry partners, university partners, and high school tech-prep teachers. 
SEATEC is actually a follow-up to a previous NSF grant titled "Tennessee Exemplary Faculty for Advanced Technology Education, TEFATE." Among other accomplishments, TEFATE produced twenty-five case studies that have been published and made available to educators. The overall objective of SEATEC is to provide a national leadership in promoting and perfecting case-based instruction in technology education. The SEATEC's approach to achieving this objective, and its accomplishments during the first year of the three-year grant is discussed below. This paper also documents activities that have brought national attention to the project and provided opportunities for SEATEC team members to exchange ideas with others working in the case study area. Field-testing of case studies written under the TEFATE grant are discussed and preliminary assessment results are shared with the reader. Efforts at furthering the professional development of participating faculty and examples of these activities are covered. The task of disseminating information relating to all aspects of SEATEC's activities has been made easier through continuing advances in electronic communication techniques. SEATEC's use of these techniques is also discussed in the paper.

\section{Summary of Activities}

To achieve the above-mentioned SEATEC goals, several projects and activities have been initiated, which include:

\section{National Leadership in Case-based Instruction}

Participating faculties from SEATEC as well as the earlier TEFATE grants have gone through a rigorous training and professional development in preparation for achieving a well recognized leadership in case-based technical education. Technical workshops and seminars were held throughout the grants periods, these include: team building, active collaborative education, and leadership training; case study development and implementation; applying multimedia in curriculum development; industry site visits; faculty internship in industry; computer based training; and procedures for applying and field-testing case studies in technology programs.

Year one of SEATEC began with the Fall 1998 Workshop, which focused on implementing case studies in technology education, the effective use of multimedia, and cooperative education using case studies. Two professional development forums titled "Characteristics of an Effective Case Study" and "Strategies for Using Case Studies in Teaching and Learning" were conducted afterward at the Peabody College, Vanderbilt University. Two panels of nationally recognized case study experts addressed questions and concerns regarding the use of the case study technique in technology education. The forums were followed by knowledge mining activities led by the Learning Technology Center (LTC) at Vanderbilt in which SEATEC faculty members shared their thoughts with the experts, industrial partners, and other members. Finally, eight new cases were presented at the 1999 summer workshop, which bore the fruits of this activity-filled year (a few more cases are still being developed).

\section{Professional Development for Participating Faculty}

A Professional Development Team was formed and conducted campus-wide in-service sessions. These sessions introduced other faculties at the five participating institutions to the benefits of 
using case studies in technology education. Numerous industrial site visits exposed the faculty to the latest technological practices in area industry and provided the basis for new "real-world" based problems which will be used in case studies.

A unique project associated with professional development is underway at Jackson State Community College. The local SEATEC team has been asked to contribute their expertise in case studies to assist the Faculty Development Committee in originating a new philosophy for faculty development activities, and to determine how this philosophy should relate to a new faculty evaluation instrument that is being developed. To accomplish this goal, the challenge will be presented to the faculty as a case study. The faculty will become the students and be divided into small study groups where they will come up with suggested solutions. This project is expected to result in improved faculty development activities as well as a better understanding of case studies. It is hoped that this real-life experience will motivate the faculty to use case studies in their classes.

An opportunity to reach out beyond the usual college setting came about with an invitation to the JSCC SEATEC team to present the case study approach to the Shelby County Public Schools faculty, meeting for an in-service day in Memphis. A great deal of interest was shown in case studies by those who attended, especially those teachers involved in Tech-Prep. Although this was not one of SEATEC's targeted groups, it did suggest that case studies could be used in K-12 technology classes to better prepare students for college courses.

\section{Assessing Effectiveness in the Case Study Approach}

The LTC at Vanderbilt http://peabody.vanderbilt.edu/ctrs/ltc/ was contracted to assess the effectiveness of the case study approach in teaching technology students. Twenty-five cases developed under the previous TEFATE grant were posted on the web and also printed for distribution across the globe. Each team identified the courses where field-testing will be conducted and assessments are being conducted. An advisory committee was also formed to monitor the progress in meeting this objective.

Several case studies have been field tested in engineering technology classes. The LTC at Vanderbilt is presently assessing the effectiveness of the case presentations. Preliminary analysis of student feedback indicates favorable response from the students. They give high marks to the real-life authenticity of the cases and to the teamwork aspect that allows the opportunity to participate in small groups. Students who are too shy to participate in regular class discussions seem to open up and contribute when placed into a small group setting. Because of the enthusiasm built up in the small group, these students will usually be willing, when called upon, to report their group's findings to the entire class. These preliminary findings appear to dispel the fears of some educators that students will not buy into case studies.

Another source of student feedback is the traditional student evaluation of the instructor that is conducted by most institutions. In the classes where a case study was presented, many students listed the case experience as the highlight of the course. They seem to view the case studies as a refreshing change from the traditional lecture. 


\section{Dissemination of Case Study Information on a National Basis}

One of the most effective tools in publicizing and promoting case studies is a video presentation featuring scenes of student involvement in case study presentations, along with interviews of selected students expressing their feelings and opinions of the case study experience. Other featured interviews on the video are with SEATEC faculty and industry representatives involved in writing or presenting the case study. The video is very well made at a state-of-the-art production facility at the Renaissance Center http://www.rcenter.org/ in Dickson, TN and has been enthusiastically received by audiences and educators wherever shown.

In addition, SEATEC members have published several papers and presented at various international, national, and regional conferences and are disseminating the preliminary results of this grant. The affiliation of these members with SEATEC provides them opportunities, as well as means to present their papers. The conferences have benefited as the new presenters share fresh ideas and concepts with their colleagues. Cases written under the TEFATE and SEATEC grants have been bound into two volumes and are available to interested parties. A web site has also been created to electronically disseminate materials, including the TEFATE cases, related to the grant http://www.nsti.tec.tn.us/SEATEC/.

\section{A Sample Case}

The authors have participated in the writing of several cases throughout the grants. A case that the author has developed is attracting the attention of various educators. It is based on the pizza warmer that the Electrical Product Division of Heatcraft in Murfreesboro, TN is manufacturing. This pizza oven is currently being used by delivery drivers and most take-out locations of a major pizza company and will be available to the public soon. The material being used for the heating element is a revolutionary sheet of plastic impregnated with carbon-composition materials and is named Polytherm ${ }^{\mathrm{TM}}$. These sheets come in various thickness and widths. The student is asked to model the warmer's electrical circuit and solve the circuit in order to calculate the resistance, current, power, and heat produced and energy consumption using an active collaborative learning approach. The case can also take various directions such as a mechanical approach (thermodynamics/heat transfer) or a business approach (engineering economy). The case is titled "I Want My Pizza Hot" with the following initial student objectives:

- Model an electrical circuit based on a real electrical load.

- Use critical thinking and apply basic algebra in problem solving.

- Convert between systems of units.

- Calculate the resistance of a material from its physical parameters.

- Apply Ohm's law in DC circuit analysis.

- Calculate power and energy.

- Conceptualize duty cycle and basic heat transfer.

- Consider electrical safety measures.

- Use spreadsheets, interpret data, and apply charting skills.

- Use software to simulate electrical circuits.

- Use oral and written communications skills to present data and conclusions. 
The heating element is shown in Figure 1. The complete case is available from SEATEC for field-testing and dissemination. In each case, the students read the story behind the product, and answer the direct and/or implicit questions that follow. Sample of direct questions from the pizza case are given below:

$>$ Please help Bob getting his badly needed sleep by listing, what you consider, the essential design requirements of the portable pizza warmer.

$>$ What do you think the advantages of Polytherm ${ }^{\mathrm{TM}}$ over a traditional heating wire?

$>$ In your opinion, why were slits made in the Polytherm ${ }^{\mathrm{TM}}$ pizza warmer? Would more slits produce more heat? Explain.

$>$ Why do you think the team used two thermostats? Is the location of the thermostats important? Explain.

$>$ How do you think the warmer's insulation materials and ambient temperature affect the duty cycle? Would the duty cycle in a colder climate be greater or smaller than that of a warmer climate? Explain.

The student is also lead through the story to questions that provoke critical thinking such as:

"Sure enough, Tom sat behind his desk and started writing in his notebook:

\section{Pizza Warmer Project Today's Date Time}

Find the resistance between two adjacent copper buses. "I have all needed parameters, that shouldn't be a sweat! For simplicity, I will assume that slits are rectangular in shape."

$>$ Find the total resistance as seen at the two terminal leads of the warmer. "Well, adding resistors in series and parallel gets me really excited!"

$>$ Find the total current when the warmer is ON. "I will assume that the voltage from the car's battery is $12 \mathrm{~V}$."

$>$ Find the power dissipated. "Since electrical power will be converted to heat, this will give me a good sense when compared to other electrical devices such as a light bulb."

$>$ Find the heat produced in the warmer over a period of one hour. "I will assume that the thermostats duty cycle is $50 \%$."

Pretend that you are Tom; can you follow his steps described above and find what he is looking for? How should you present your findings to Bob? Would a "scratch paper" type report be OK? Explain?"

Additional questions that extend the case further are also included, such as:

$>$ Pretend that you are Bob; explain how the bag works to your children in a way that they can understand.

$>$ Make a list of other possible uses for this technology.

$>$ Research the patent process. Pretend that you are Bob; apply for a patent for your new pizza warmer invention. 


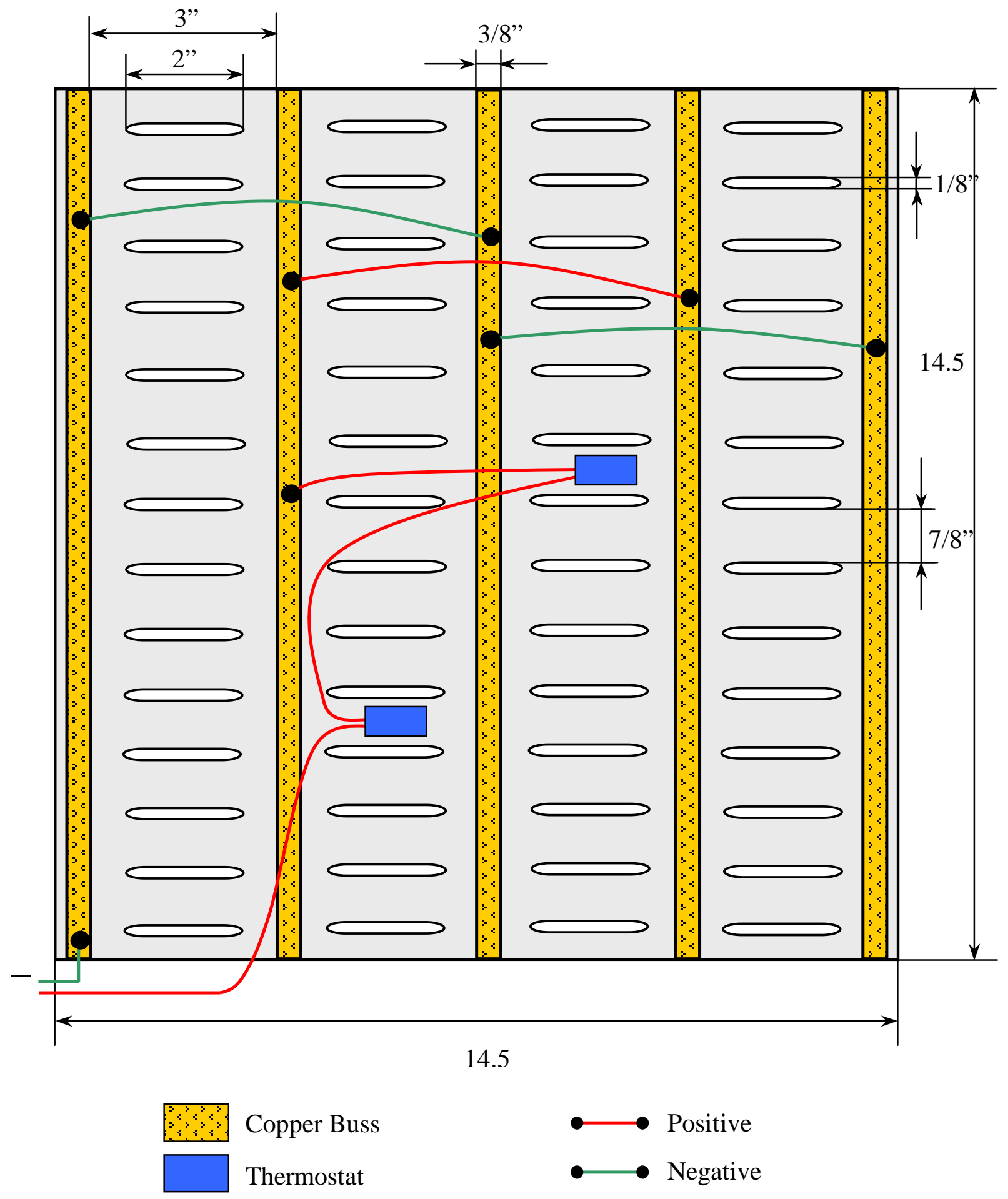

Figure 1. Polytherm ${ }^{\mathrm{TM}}$ Pizza Warmer Heating Element. 
$>$ Now that your instructor has assigned each of you to a team, develop a team presentation for one alternative use of this technology and "sell" your new product to your classmates in an oral team presentation.

$>$ Pretend that you are Bob; design a presentation to sell the pizza warmer to a business. What type of businesses would be interested in this invention? What differences will you have to consider when preparing your presentation to these different companies?

V. Summary

The idea that traditional methods of technical education can be improved upon seems to be catching on. Case-based learning is getting a good hearing through the efforts of SEATEC. SEATEC-sponsored seminars and workshops have been well attended by experts in the field, as well as educators who are anxious to learn more. Students who are exposed to case studies for the first time are enthusiastic in their responses. The partnership between technical colleges and industry is growing stronger as they work together to develop real-life cases and reap the rewards of better-trained employees. Case studies developed under the TEFATE grant are being publicized and made available to more educators. Better still, educators are being trained and motivated to develop case studies that fit their own particular situations. The word is out that there is a well-trained, enthusiastic group of educators willing to assist those who want to be involved in improving education through case-based learning.

\section{Acknowledgments}

The authors wish to express their sincere gratitude to the National Science Foundation for providing the means to execute this project and to every member of the TEFATE and SEATEC family.

This project was supported, in part, by the National Science Foundation. Opinions expressed are those of the author and not necessarily of the Foundation.

\section{SALEH SBENATY}

Dr. Saleh M. Sbenaty is currently an Associate Professor in the Department of Engineering Technology \& Industrial Studies at Middle Tennessee State University. He received the BS degree in Electrical Engineering from Damascus University, Syria and the MS and Ph.D. degrees in EE from Tennessee Technological University. He is actively engaged in curriculum development for Engineering and technology education and research in the area of mass spectrometry, power electronics, and instrumentation. He is the team leader for the Nashville Tech. SEATEC team.

\section{MELVIN MONTGOMERY}

Melvin Montgomery is currently an Assistant Professor of Engineering Technology at Jackson State Community College. He received a BS degree in Electrical Engineering from Brigham Young University. He is an active member of the JSCC SEATEC team. Before coming to Jackson State 5 years ago, he spent 36 years in industry as an instrumentation and controls engineer. 